\title{
Frequency of fear of fall among diabetic patients in Hayatabad Medical Complex Peshawar
}

\author{
Adnan Khan ${ }^{1}$, Tajamul Ahmad ${ }^{2}$, Nadia Afridi ${ }^{3}$, Madiha Anees ${ }^{4}$, Bilal Khan ${ }^{5}$
}

\section{Submitted: \\ May 4, 2020 \\ Accepted: \\ July 5, 2020}

\section{Author Information}

${ }^{1-5}$ Rehman College of Rehabilitation Sciences

\begin{abstract}
Introduction: A fall may be defined as a loss of balance, resulting in coming to rest on the ground or on another object below knee level. Fear of all or Basophobia is a condition of concern towards falls and natural fear of unable to stand or walk. Since the identification of the post-fall syndrome, fear of fall is considered the major health issue among elderly population. Therefore, this study was conducted to measure the level of fear of fall and factors which might contribute to it.

Material \& Methods: It was a cross sectional study conducted to measure the level of fear of fall among the diabetic patients of Hayatabad Medical Complex Peshawar. According to the inclusion criteria, participants who had age more than 40 years and diabetic history of more than 2 years were included in the study. We measured the fear of fall with age, gender and duration of diabetes mellitus. Convenient sampling technique was used for the recruitment of the participants. Data was collected by self-repored questionnaires and was analyzed by SPSS 20.0 version.

Results: A total of 306 participants, 164 (53.59\%) males and 142 (46.40\%) female with a mean age $56.02 \pm$ 9.68 years (mean $\pm \mathrm{sd}$ ) were recruited. The level of fear of all was high in diabetic patients in which 222 (72.5\%) participants showed high, 48 (15.7\%) moderate and $36(11.8 \%)$ low concerns.

Conclusion: Fear of fall is a common problem in both male and female population having diabetes mellitus. It is one of the major concerns among patients with diabetes. It has a positive relation with age, duration of $\mathrm{DM}$, and insulin intake

Key Words: Diabetics Mellitus, Fall, Fear of fall, Fall Efficacy Scale
\end{abstract}

The authors declared no conflict of interest and agreed to be accountable for all aspects of the work in ensuring that questions related to the accuracy or integrity of any part of the work are appropriately investigated and resolved.All authors contributed substantially to the planning of research, questionnaire design, data collection, data analysis and write-up of the article as part of a student research team at Rehman College of Rehabilitation Sciences.The research work was supervised by Dr. Bilal Khan (PT) Assistant Professor Rehman College of Rehabilitation Sciences

This article may be cited as:Khan A, Ahmad T, Afridi N, Anees M, Khan B. Frequency of fear of fall among diabetic patients in Hayatabad Medical Complex Peshawar. Rehman J Health Sci. 2020;2(1). 14-18

\section{INTRODUCTION}

A fall may be defined as a loss of balance resulting in coming to rest on the ground or on another object below knee level, whereas fear of fall (FOF) or "Basophobia" is a condition of concern towards falls and natural fear of being unable to stand or walk. ${ }^{1,2}$ Fear of falling is a psychological factor which influences a person ability to avoid it. ${ }^{3}$ Since the identification of the post-fall syndrome, FOF is considered to be the major health issue among elderly population. ${ }^{4}$ FOF influences patient's walking ability, balance and its characteristics to fall. ${ }^{5}$ Fear of future fall occur commonly due to the history of previous falls or without any history. ${ }^{6}$ Participants in one study indicated that they did not consider themselves as being 'afraid of falling' but rather were 'worried' about falling. ${ }^{4}$ The association of FOF was examined among older individuals and association between FOF and gender was observed. ${ }^{7}$ Deficit in balance or steadiness are thought to be one of the predictors for the developing of fear of fall. ${ }^{8}$ Fall can occur due to various extrinsic factors; including poor lighting, inappropriate rugs and other environmental hazards while physiological changes associated with increasing age, orthostatic hypotension, anaemia, Parkinson's disease, certain medications, diabetes mellitus, cognitive problems, syncope, partial complex seizures and vitamin D deficiency are intrinsic factor. ${ }^{9}$ After motor vehicles accidents, falls are the second substantial contributor to the economic burden of injuries. Aging is considered to be the main reason for fall. ${ }^{10}$ Falls are the sixth leading cause of death in Canada and fourth most common cause of death in men aged between $65-85$ years. ${ }^{11}$ In the United States, about $3 / 4$ of deaths occurs due to falls in $13 \%$ of the population of aged $\geq 65$ years. About $40 \%$ of this age group living at home will fall at least once a year. Although most of these falls result in no consequential injury, about $5 \%$ do result in a fracture or require hospitalization. Moreover, the risk of fall and its complications increases with increasing age, twice these figures for persons aged $>75$ years. ${ }^{12}$ Falls are foremost cause of morbidity and mortality in the older adults the USA. It has been reported that with increasing age, the economic burden of falls may reach $\$ 54.9$ billion in $2020 .^{6}$ According to the World Health Organization (WHO) report, 283,000 people died in 2000 as a result of falls. The latter report suggested that the mortality rate due to fall in Europe and North America ranged from 6.5 to 11.3 per 100,000 and 2.1 per 100,000 in India it is. ${ }^{13}$ 
One determinant now established as a leading predictor for fall is diabetes mellitus. ${ }^{14}$ Diabetes is described as a series of metabolic diseases represented by hyperglycaemia resulting from abnormal secretion of insulin and its action or both. ${ }^{15} \mathrm{DM}$ causes numerous systemic complications including diabetic peripheral neuropathy (DPN), present in $50 \%$ of DM patients, which results in sensory, motor and autonomic dysfunction which could contribute to falls. ${ }^{14}$ While studying the association of FOF with type 2 diabetes mellitus, it showed that mobility is affected by FOF and fear related restrictions of activities. ${ }^{16}$ Prospective studies have demonstrated that elderly diabetic patients treated with insulin are at high risk of falls. ${ }^{17}$ Patients having severe FOF leads to the activity and participation restriction of patients thus resulting in deconditioning. ${ }^{5}$ FOF is prevalent in older adults but its relevance is irrespective of the level of neuropathy in diabetic patients despite its presence in $40 \%$ of patients. ${ }^{6,16,18}$ Fear can also lead to self-isolation and decreased mobility that diminishes quality of life. ${ }^{19}$

Fall has been a major concern in the elderly population and in Pakistan this rate is predicted to be increasing in near future.

Diabetic neuropathy may not have considered as it can induce fall in patients, therefore, this study was conducted to report the levels of fear of falls and its correlates with diabetic patients.

\section{MATERIALS \& METHODS}

This was a cross sectional survey to measure the levels of FOF among diabetic patients and was conducted in Hayatabad Medical Complex Peshawar. The duration of this study was 4 months from October 2018 to February 2019. A total of 306 participants were required as calculated through online calculator OpenEpi.com. Data was collected from participants by convenient sampling technique. Inclusion criteria included diabetic patients with age above 40 and having diabetic history for at least 2 years. Patients having history of stroke, amputation and diseases other than diabetes were excluded. Participants were invited to be the part of the survey and were explained the importance of this survey.

Those who agreed and signed the consent form were recruited in this study. The questionnaire was based on Likert scale. Participants were given a choice either to fill the form by themselves or by the researcher for better understanding. After the approval of graduate committee, permission was taken from head of Hayatabad Medical Complex and data was collected using Fall Efficacy Scale-I questionnaire. The questionnaire consisted of seven questions, each of them had four options that are; not at all concern, somewhat concern, fairly concern and high concern having score of 1, 2, 3 and 4 respectively. Total score was added at the end. Scoring of 7-8 showed low concern, 9-13 showed moderate concern and 14-28 high concern. Data was recorded and analysed using SPSS Version 20. Frequencies were calculated for age, gender, duration of diabetes, diabetic neuropathy and antidiabetic drugs and their correlation with FOF was found using chi-square test and Spearman test.

\section{RESULTS}

The response rate of participants was 100\%. Among the total sample, 164 (53.59\%) participants were males and 142 (46.40\%) were females with the $56.02 \pm 9.68$ years (age $\pm \mathrm{sd}$ ). The minimum age was reported to be 40 years and maximum age to be 88 years. (Table 1).

Table 1: Demographics detail of the included participants

\begin{tabular}{|c|c|c|c|c|c|c|}
\hline \multirow[t]{2}{*}{ Gender } & \multicolumn{4}{|c|}{ Age Group } & \multirow[t]{2}{*}{ Total } & \multirow[t]{2}{*}{ Mean \pm S.D Age } \\
\hline & $40-49$ years & $50-59$ years & $60-69$ years & $70+$ years & & \\
\hline Males & 42 & 63 & 41 & 18 & 164 & \\
\hline Females & 46 & 38 & 36 & 22 & 142 & $56.02 \pm 9.68$ \\
\hline Total & $88(28.8 \%)$ & $101(33 \%)$ & $77(25.2 \%)$ & $40(13.1 \%)$ & 306 & \\
\hline
\end{tabular}

Among the total sample, 112(36.6\%) had diabetic history of 3-7 years, 92 (30.1\%) had diabetic history of $8-12$ years, 48 (15.7) individuals had diabetic history of 13-17 years while 54 (17.6\%) participants had diabetic history of more than 17 years. Regarding Glucophage and insulin intake, 176 (57.51\%) participants were taking both Glucophage and insulin, 66 (21.56\%) individuals were taking only Glucophage, 63 (20.58\%) were taking insulin only and $1(0.006 \%)$ was neither taking Glucophage nor insulin. (Table 2)

Table 2: Metformin and insulin intake

\begin{tabular}{|c|c|c|}
\hline Metformin & \multicolumn{2}{|c|}{ Insulin } \\
\hline & Yes & $66(21.56 \%)$ \\
\hline Yes & $176(57.51 \%)$ & $1(0.006 \%)$ \\
\hline No & $63(20.58 \%)$ & $67(21.89 \%)$ \\
\hline Total & $239(78.10 \%)$ & 60 \\
\hline
\end{tabular}


Among the total sample, 102 participants were having diabetic neuropathy among which 8 had diabetic history of 3-7 years, 38 had diabetic history of 8-12 years while 17 had diabetic of 13-17 years and 39 had more than 18 years of diabetic history. Among 306 participants, 222 (72.5\%) showed high concern, while moderate and low concern were present in 48 (15.7\%) and 36 (11.8\%) participants respectively. For the variable of concern getting dressed or undressed, about 82 individuals (26.8\%) were fairly concerned about falling and 69 individuals (22.5\%) were somewhat concerned about falling. While taking bath or shower, 102 individuals (33.3\%) were fairly concerned while 57 participants (18.6\%) were not at all concerned about falling. For getting in or out of chair, 91 participants (29.7\%) were fairly concerned while 54 individuals (17.6\%) were very concerned about falling. For going up or down stairs, 136 participants (44.4\%) were very concerned about falling and 53 participants (17.3\%) were somewhat concerned about falling. For reaching overhead, 115 participants (37.6\%) were somewhat concerned about falling and 40 participants (13.1\%) were fairly concerned about falling. For walking up or down the slope, 149 individuals (48.7\%) were very concerned of falling and 45 participants (14.7\%) were somewhat concerned of falling. For going on social events, 197 individuals (64.4\%) were not at all concerned about falling and 21 participants $(6.9 \%)$ were fairly concerned about falling. (Table 3)

\section{Table 3: Response of participants on Fall efficacy scale}

\begin{tabular}{|l|l|l|l|l|}
\hline & \multicolumn{1}{|c|}{$\begin{array}{c}\text { Not at all } \\
\text { concerned }\end{array}$} & \multicolumn{1}{|c|}{$\begin{array}{c}\text { Somewhat } \\
\text { concerned }\end{array}$} & \multicolumn{1}{|c|}{$\begin{array}{c}\text { Fairly } \\
\text { concerned }\end{array}$} & \multicolumn{1}{|c|}{ concerned } \\
\hline Getting dressed or undressed & $77(25.2 \%)$ & $69(22.5 \%)$ & $82(26.8 \%)$ & $78(25.5 \%)$ \\
\hline Taking a bath or shower & $57(18.6 \%)$ & $65(21.2 \%)$ & $102(33.3 \%)$ & $82(26.9 \%)$ \\
\hline Getting in or out of a chair & $78(25.5 \%)$ & $83(27.1 \%)$ & $91(29.7 \%)$ & $54(17.6 \%)$ \\
\hline Going up or down stairs & $46(15 \%)$ & $53(17.3 \%)$ & $71(23.2 \%)$ & $136(44.4 \%)$ \\
\hline Reaching over head/ ground & $94(30.7 \%)$ & $115(37.6 \%)$ & $40(13.1 \%)$ & $57(18.6 \%)$ \\
\hline Walking up or down a slope & $49(16 \%)$ & $45(14.7 \%)$ & $63(20.6 \%)$ & $149(48.7 \%)$ \\
\hline Going out to a social event & $197(64.4 \%)$ & $64(20.9 \%)$ & $21(6.9 \%)$ & $24(7.8 \%)$ \\
\hline Total Level of concern & Low concern & Moderate concern & High concern & \\
\hline Total score & $36(11.8 \%)$ & $48(15.7 \%)$ & $222(72.5 \%)$ & \\
\hline
\end{tabular}

Regarding association of FOF with metformin intake, no significant correlation was found ( $p$ value 0.882 ). Association of FOF with gender also showed no significant correlation with a $p$ value of 0.166 . When association of FOF was checked with years since diagnosis of diabetes, those in the time duration of 8-12 years showed highest concerned in $76(24.8 \%)$ with p-value 0.00 . (Table 4)

Table 4: Association of FOF with duration of diabetes

\begin{tabular}{|l|c|c|c|c|c|}
\hline \multirow{2}{*}{ Duration of diagnosis } & \multicolumn{3}{|c|}{ Level of concern } & Total & P Value \\
\hline & $\begin{array}{c}7-8 \\
\text { (low concern) }\end{array}$ & $\begin{array}{c}9-13 \\
\text { (moderate concern) }\end{array}$ & $\begin{array}{c}14-28 \\
\text { (high concern) }\end{array}$ & \\
\hline $3-7$ years & $27(8.8 \%)$ & $27(8.8 \%)$ & $58(19.0 \%)$ & $112(36.6 \%)$ \\
\hline $8-12$ years & $4(1.3 \%)$ & $12(3.9 \%)$ & $76(24.8 \%)$ & $92(30.1 \%)$ \\
\hline $13-17$ years & $1(0.3 \%)$ & $4(1.3 \%)$ & $43(14.1 \%)$ & $48(15.7 \%)$ & 0.00 \\
\hline $18+$ years & $4(1.3 \%)$ & $5(1.6 \%)$ & $45(14.7 \%)$ & $54(17.6 \%)$ & $306(100.0 \%)$ \\
\hline Total & $36(11.8 \%)$ & $48(15.7 \%)$ & $222(72.5 \%)$ & 300 \\
\hline
\end{tabular}

Regarding coorelation of FOF with age, a significant correlation was found with a $\mathrm{p}$ value of 0.00 showing highest concern in the individuals between the age of 50 to 59 years. (Table 5) 
Table 5: Coorelation of FOF with age

\begin{tabular}{|l|c|c|c|c|c|}
\hline \multirow{2}{*}{ Age Group } & \multicolumn{3}{|c|}{ Level of concern } & Total & P Value \\
\hline & $\begin{array}{c}7-8 \\
\text { (low concern) }\end{array}$ & $\begin{array}{c}9-13 \\
\text { (moderate concern) }\end{array}$ & $\begin{array}{c}14-28 \\
\text { (high concern) }\end{array}$ & \\
\hline $40-49$ years & $24(7.8 \%)$ & $14(4.6 \%)$ & $50(16.3 \%)$ & $88(28.8)$ \\
\hline $50-59$ years & $8(2.6 \%)$ & $22(7.2 \%)$ & $71(23.2 \%)$ & $101(33.0 \%)$ \\
\hline $60-69$ years & $1(1.0 \%)$ & $11(3.6 \%)$ & $63(20.6 \%)$ & $77(25.2 \%)$ \\
\hline $70+$ years & $1(0.3 \%)$ & $1(0.3 \%)$ & $38(12.4 \%)$ & $40(13.1)$ \\
\hline Total & $36(11.8 \%)$ & $48(15.7 \%)$ & $222(72.5 \%)$ & $306(100 \%)$ \\
\hline
\end{tabular}

Insulin was found to be directly influencing FOF ( $p$ value 0.00 )

with $188(61.4 \%)$ population showing highest concern of fear of fall. (Table 6)

Table 6: Coorelation of FOF with Insulin intake

\begin{tabular}{|l|c|c|c|c|c|}
\hline \multirow{2}{*}{ Insulin Intake } & \multicolumn{3}{|c|}{ Levels of concern } & Total & P Value \\
\hline & $\begin{array}{c}7-8 \\
\text { (low concern) }\end{array}$ & $\begin{array}{c}\text { 9-13 } \\
\text { (moderate concern) }\end{array}$ & $\begin{array}{c}14-28 \\
\text { (high concern) }\end{array}$ & \\
\hline Yes & $18(5.9 \%)$ & $33(10.8 \%)$ & $188(61.4 \%)$ & $239(78.1 \%)$ & 0.00 \\
\hline No & $18(5.9 \%)$ & $15(4.9 \%)$ & $34(11.1 \%)$ & $67(21.9 \%)$ \\
\hline Total & $36(11.8 \%)$ & $48(15.7)$ & $222(72.5)$ & $306(100 \%)$ & \\
\hline
\end{tabular}

Diabetic neuropathy also influenced FOF significantly ( $\mathrm{p}$ value concern of FOF (44.1\%). (Table 7) 0.002 ) with those without diabetic neuropathy showing highest

Table 7: Coorelation of FOF with diabetic neuropathy

\begin{tabular}{|l|c|c|c|c|c|}
\hline \multirow{2}{*}{ Diabetic Neuropathy } & \multicolumn{3}{|c|}{ Level of concern } & Total & P Value \\
\hline & $\begin{array}{c}7-8 \\
\text { (low concern) }\end{array}$ & $\begin{array}{c}9-13 \\
\text { (moderate concern) }\end{array}$ & $\begin{array}{c}14-28 \\
\text { (high concern) }\end{array}$ & \\
\hline Yes & $7(2.3 \%)$ & $8(2.6 \%)$ & $87(28.4 \%)$ & $102(33.3 \%)$ & 0.002 \\
\hline No & $29(9.5 \%) 3$ & $40(13.1 \%)$ & $135(44.1 \%)$ & $204(66.7 \%)$ & $306(100 \%)$ \\
\hline Total & $6(11.8 \%)$ & $48(15.7 \%)$ & $222(72.5 \%)$ & \\
\hline
\end{tabular}

\section{DISCUSSION}

This study was a cross sectional survey in which 306 participants were participated. The purpose of this study was to assess FOF among diabetic patients. Our results showed low, moderate and high concern of falling in $36(11.8 \%), 48$ (15.7\%) and 222 (72.5\%) of the participants, respectively. The main contributing factors to FOF included age, duration of diabetes and insulin intake which showed high concern of FOF compared to gender, metformin intake and diabetic neuropathy. A study conducted in Chicago, concluded that most participants in the study demonstrated moderate (38.2\%) to high (44.2\%) concern about falling. ${ }^{18}$ Findings of the latter study are in accordance to our study where a high concern of falling was reported by majority of the participants. There seems a bit of differences between our trial and the latter trail. These differences might be due to inclusion of other variables like $20 \mathrm{~m}$ walk, gait parameters and balance during walk using different tests. Their study did not show any correlation with diabetic neuropathy similar to our study. Their study reflected same level of concern between participants with and without diabetic neuropathy but in our study the level of concern was high in participants with no diabetic neuropathy when compared with participants having diabetic neuropathy. The reason of this contradiction may be due to the presence of $67 \%$ participants with no diabetic neuropathy at all. With regard to the age of 
participants, their study indicated high frequency of FOF in older population which is similar to our study where a high concern was shown $71 \%$ of the participants having age $>50$ years.

In our study, FOF showed a significant correlation with duration of diabetes. High Level of concern was present in $51.8 \%$ in participants who had 3-7 years of diabetic history, $82.6 \%$ participants having diabetic history of $8-12$ years and $89.6 \%$ participants who had diabetic history of $13-17$ years and $83.3 \%$ participants showed high concern having diabetic history of more than 18 years. Similar findings were reported in a study carried out to find out FOF among diabetic and non-diabetic population. According to this study, FOF was significantly influenced by ageing with duration of diabetes. ${ }^{20}$ Gender remained one of the reported contributing factors to FOF in diabetic population. In a study carried out on 350 participants, female were reported to have greater FOF compared to their counterparts male population. ${ }^{7}$ Findings of our trial is not in accordance to the results of the latter study where no association was found between FOF and gender in our study. This difference in results could be because of difference in age which was not similar in our study and the latter study. Fear of falling at baseline as a predictor of fall came out to be the result of a study to find relation between falls and FOF. One of the trials reported that fear of falling could be predicted by age, and taking four or more medications. ${ }^{21}$ Regarding medications of diabetes mellitus, a study reported significant relation of these drugs with falls and risk of falls. ${ }^{17}$ The latter study stated that
Metformin was considered as first line therapy in early diagnosis of diabetes mellitus and was not directly related to risk of fall but on the other hand use of insulin was associated with risk of fall. Similarly, in comparison with our study there was no significant correlation between FOF and metformin, however, insulin showed a significant correlation with FOF.

\section{CONCLUSION}

Fear of fall is a common problem in both male and female population having diabetes mellitus. It is one of the major concerns among patients with diabetes mellitus specially in patients with chronic condition. Female gender is more prone to develop fear of fall compared to their counterpart's male population. It has positive relation with age, duration of DM, and insulin intake.

\section{RECOMMENDATIONS}

The current results show that hospital management should emphasize on awareness of FOF and preventive measures as well as early detection of the FOF.

\section{LIMITATIONS}

The sampling technique was convenient rather than randomized sampling. Other variables such as other medical conditions which were present in the participants were not included.

\section{REFERENCES}

1. Wiles CM, Busse ME, Sampson CM, Rogers MT, Fenton-May J, van Deursen R. Falls and stumbles in myotonic dystrophy. Journal of Neurology, Neurosurgery \& Psychiatry. 2006; 77:393-6.

2. Dewan N, MacDermid JC. Fall efficacy scale-international (FES-I). Journal of physiotherapy. 2014;60:60.

3. Li F, Fisher KJ, Harmer P, McAuley E, Wilson NL. Fear of falling in elderly persons: association with falls, functional ability, and quality of life. The Journals of Gerontology Series B: Psychological Sciences and Social Sciences. 2003; 58:P283-P90.

4. Legters K. Fear of falling. Physical therapy. 2002; 82:264-72.

5. Delbaere K, Close JC, Brodaty H, Sachdev P, Lord SR. Determinants of disparities between perceived and physiological risk of falling among elderly people: cohort study. Bmj. 2010; 341:c4165.

6. Delbaere K, Crombez G, Vanderstraeten G, Willems T, Cambier D. Fear-related avoidance of activities, falls and physical frailty. A prospective community-based cohort study. Age and ageing. 2004; 33:36873.

7. Filiatrault J, Desrosiers J, Trottier L. An exploratory study of individual and environmental correlates of fear of falling among community-dwelling seniors. Journal of aging and health. 2009; 21:88194.

8. Lach HW. Incidence and risk factors for developing fear of falling in older adults. Public health nursing. 2005; 22:45-52.

9. Romli M, Tan M, Mackenzie L, Lovarini M, Suttanon P, Clemson L. Falls amongst older people in Southeast Asia: a scoping review.
Public Health. 2017; 145:96-112.

10. Heinrich S, Rapp K, Rissmann U, Becker C, König H-H. Cost of falls in old age: a systematic review. Osteoporosis international. 2010; 21:891-902.

11. Long L. Fall prevention \& intervention in home care. Caring: National Association for Home Care magazine. 2003; 22:8-10.

12. Rubenstein LZ. Falls in older people: epidemiology, risk factors and strategies for prevention. Age and ageing. 2006; 35:ii37-ii41.

13. Johnson S. Frequency and nature of falls among older women in India. Asia Pacific Journal of Public Health. 2006; 18:56-61.

14. Lalli P, Chan A, Garven A, Midha N, Chan C, Brady $S$, et al. Increased gait variability in diabetes mellitus patients with neuropathic pain. Journal of Diabetes and its Complications. 2013; 27:248-54.

15. Association AD. Diagnosis and classification of diabetes mellitus. Diabetes care. 2014; 37:S81-S90.

16. Bruce D, Hunter M, Peters K, Davis T, Davis W. Fear of falling is common in patients with type 2 diabetes and is associated with increased risk of falls. Age and ageing. 2015; 44:687-90.

17. Berlie HD, Garwood CL. Diabetes medications related to an increased risk of falls and fall-related morbidity in the elderly. Annals of pharmacotherapy. 2010; 44:712-7.

18. Kelly C, Fleischer A, Yalla S, Grewal GS, Albright R, Berns D, et al. Fear of falling is prevalent in older adults with diabetes mellitus but is unrelated to level of neuropathy. Journal of the American Podiatric Medical Association. 2013; 103:480-8.
19. Brownsell S, Hawley MS. Automatic fall detectors and the fear of falling. Journal of telemedicine and telecare. 2004; 10:262-6.

20. Tander B, Atmaca A, Ulus Y, Tura Ç, Akyol Y, Kuru Ö. Balance performance and fear of falling in older patients with diabetics: a comparative study with non-diabetic elderly. Turkish Journal of Physical Medicine \& Rehabilitation/Turkiye Fiziksel Tip ve Rehabilitasyon Dergisi. 2016; 62.

21. Friedman SM, Munoz B, West SK, Rubin GS, Fried LP. Falls and fear of falling: which comes first? A longitudinal prediction model suggests strategies for primary and secondary prevention. Journal of the American Geriatrics Society. 2002; 50:132935. 